\title{
Studi Deskriptif Mengenai Happiness pada Mahasiswa Pengguna Media Sosial di Kota Bandung
}

\author{
Dzar Nurul Halimah *, Endah Nawangsih \\ Prodi Psikologi, Fakultas Psikologi, Universitas Islam Bandung, Indonesia. \\ *dzarnurul28@gmail.com, endah.nawangsih@unisba.ac.id
}

\begin{abstract}
Seligman explain that happiness is a measurement towards ourselves and life, those are including a positive emotions like a convenience and an overflowing happiness, or the positive activity that doesn't fulfill with any emotions such an absorption and involvement (Seligman, 2005). In this research, there are so many positive effects that the students felt as make the interact with people easly, as an educational media, entertainment, and to fill their free time. Instead of that, so negative efects does, such as forget about the time cause of they want to keep connected, they was envy with people's life in social media, and they feel hard to build a relations in real life. The result are $95 \%$ students feel positive emotion, engagement $95 \%$, relationships $100 \%$, meaning 96,7\%, accomplishment $95 \%$, negative emotion $18,3 \%$, and health $96,7 \%$. It shown conclude of this research that almost all of the students or 177 subjects have high level of happiness.
\end{abstract}

Keywords: Happiness, Social Media, Collage Students.

\begin{abstract}
Abstrak. Seligman menjelaskan kebahagiaan merupakan suatu hasil penilaian terhadap diri dan hidup, yang memuat emosi positif seperti kenyamanan dan kegembiraan yang meluap-luap, maupun aktivitas positif yang tidak memenuhi komponen emosi apapun seperti absorbsi dan keterlibatan (Seligman, 2005). Pada penelitian ini banyak hal yang dihayati oleh subjek, antara lain dampak positif seperti memudahkan interaksi dengan orang lain, sebagai media edukasi, hiburan, dan untuk mengisi waktu luang. Ada pula dampak negatif yang dirasakan ketika mengakses media sosial, seperti lupa waktu karena ingin terus terkoneksi, timbul rasa iri karena membandingkan hidup mereka dengan orang lain, serta bentuk pelarian karena sulitnya membangun relasi dan interaksi di dunia nyata. Hasilnya sebanyak $95 \%$ subjek merasakan positive emotion, engagement sebanyak 95\%, relationships sebanyak $100 \%$, meaning sebanyak 96,7\%, accomplishment sebanyak 95\%, negative emotion sebanyak $18,3 \%$, serta health sebanyak 96,7\%. Maka secara keseluruhan mahasiswa yang menjadi subjek memiliki tingkat happiness yang tinggi, yaitu sebanyak 177 orang atau $98,3 \%$.
\end{abstract}

Kata Kunci: Happiness, Media Sosial, Mahasiswa. 


\section{Pendahuluan}

Banyak yang menyadari, pengguna yang mengabaikan aktifitas sosial dan kegiatan waktu luangnya tapi tidak mampu keluar dari jeratan dunia virtual. Pengguna tidak bisa lagi mengendalikan konsumsinya akan internet. Semenjak situs jejaring sosial banyak diminati oleh semua kalangan pengguna rela menghabiskan waktu berjam-jam hanya untuk mengunjungi situs tersebut, tanpa mengetahui alasan yang sesungguhnya, terutama pada kalangan remaja dan dewasa awal seperti mahasiswa. Data hasil survey yang dilakukan oleh Asosiasi Penyelenggara Jasa Internet Indonesia (APJII) pada tahun 2016 menemukan bahwa statistik pengguna internet di Indonesia berdasarkan profesi atau pekerjaan, didominasi oleh mahasiswa.

Beberapa mahasiswa mengungkapkan bahwa penggunaan sosial media yang diakses secara terus-menerus biasanya dilakukan untuk menghilangkan rasa bosan, dan mengisi waktu luang. Terlebih sebagian besar dari mereka merasa bahwa sosial media adalah sebuah kebutuhan yang harus dipenuhi. Sehingga ketika mereka sedang tidak terkoneksi mereka merasa cemas dengan berbagai alasan seperti, tidak ingin ketinggalan berita dari dunia maya, merasa harus membalas semua pesan yang diterima dengan segera, merasa harus selalu terkoneksi karena bisa membuat mereka dipandang mengikuti perkembangan zaman sebagaimana yang dilakukan orang-orang pada generasi saat ini.

Hasil wawancara kepada sejumlah mahasiswa tersebut ditemukan bahwa sebagian dari mereka merasakan dampak negatif yang dialami, seperti overtime dari rencana awal yang seharusnya mereka pakai untuk mengakses internet sehingga lupa waktu, mengabaikan kewajiban-kewajiban mereka sebagai mahasiswa yang harus menyelesaikan berbagai macam tugas namun seringkali teralihkan karena dorongan yang besar untuk selalu terkoneksi, berkurangnya kualitas hubungan dengan orang lain di dunia nyata karena mereka merasa bahwa dunia maya bisa lebih menumbuhkan perasaan yang menyenangkan. Kenyataan tersebut memungkinkan bahwa terjadinya perubahan-perubahan kondisi psikologis dalam diri individu saat melakukan akses ke media sosial.

\section{Landasan Teori \\ Happiness}

Dari kaca mata psikologi positif, kebahagiaan merupakan tema utama meski dipandang sebagai konsep abstrak. Tiga elemen dasar dari kebahagiaan (happiness) adalah emosi positif (positive emotions), keterlibatan (engangement) dan makna hidup (meaning). Dalam pengukuran kebahagiaan maka diturunkan dalam konsep well being yang dalam pengukurannya memiliki lima elemen yang dapat disingkat menjadi PERMA, yaitu (P) Positive Emotion, (E) Engagement, (R) Relationship, (M) Meaning and Purpose, dan (A) Accomplishment (Seligman).

Myers (2007) menyatakan bahwa kebahgiaan adalah pengalaman hidup yang ditandai oleh perasaan positif seperti perasaan bahagia dan pikiran yang mengarah pada kepuasan kehidupan. Berdasarkan uraian diatas maka dapat disimpulkan bahwa kebahagiaan merupakan kondisi perasaan seseorang sebagai respon afeksi terhadap berbagai pengalaman kehidupanya. Seseorang yang bahagia ditandai oleh lebih banyaknya perasaan positif daripada perasaan negatifnya. Sebaliknya, seseorang yang tidak bahagia ditandai dengan lebih banyaknya perasaan negatif daripada perasaan positifnya.

Kebahagiaan merupakan evaluasi yang dilakukan seseorang terhadap hidupnya, mencakup segi kognitif dan afeksi. Evaluasi kognitif sebagai komponen Kebahagiaan seeorang diarahkan pada penilaian kepuasan individu dalam berbagai aspek kehidupan, seperti pekerjaan, keluarga dan pernikahan. Sedangkan evaluasi afektif merupakan evaluasi mengenai seberapa sering seseorang mengalami emosi positif dan negatif (Diener dalam Astuti, 2007). Kebahagiaan merupakan konsep yang subjektif karena setiap individu memiliki tolak ukur kebahagiaan yang berbeda-beda. Setiap individu juga memiliki faktor yang berbeda sehingga bisa mendapatkan kebahagiaan untuknya.

Elemen Happiness :

1. Positive emotion 
Emosi positif meliputi perasaan bahagia, senang, nyaman, berhasrat, dan sebagainya. Emosi positif juga meliputi perasaan optimis terhadap kehidupannya di masa lalu, saat ini, dan masa depan.

2. Engangement

Penting dalam hidup kita untuk dapat menemukan aktivitas yang membutuhkan keterikatan penuh. Keterikatan dalam aktivitas kehidupan kita merupakan hal yang penting untuk dipelajari, ditumbuhkan dan dipertahankan untuk kebahagiaan diri.

3. Relationships

Hubungan dan relasi social merupakan salah satu dari aspek penting dalam kehidupan. Manusia merupakan makhluk social yang mengembangkan hubungan dengan pesat, cinta, intimasi, dan emosi yang kuat serta interaksi fisik dengan manusia lain. Dalam membangun hubungan yang positif dengan orang tua, saudara, sahabat dan teman dekat penting untuk menyebarkan cinta dan kebahagiaan.

4. Meaning

Pemaknaan merupakan memiliki tujuan dalam kehidupan, mampu menentukan arah hidupnya, merasa bahwa hidup itu bernilai dan layak untuk dinikmati, serta terlibat dnegan sesuatu yang lebih besar dari dirinya. Seperti keyakinan religious dan aktivitas social. Pemaknaan memberikan kesadaran pada diri seseorang bahwa kehidupannya penting dan bermakna.

5. Accomplishment

Memiliki tujuan dan ambisi dalam kehidupan dapat membantu kita dalam meraih sesuatu yang dapat memberi kita rasa pencapaian diri. Kamu harus membuat tujuan yang realistis yang dapat ditemukan. Dan hanya dengan memberikan usaha untuk meraihnya dapat memberikan rasa kepuasan. Ketika kamu akhirnya meraih tujuan tersebut rasa bangga dan pemenuhan akan diraih. Memiliki pencapaian dalam hidup penting untuk mendorong kita agar tumbuh dan berkembang.

6. Negative Emotion

Emosi negatif bukan merupakan bagian dari model PERMA, namun merupakan bagian dari emosi. Emosi negtaif meliputi perasaan-perasaan seperti sedih, cemas, dan marah.

7. Health

Walaupun kesehatan (health) bukan merupakan bagian dari model PERMA, kesehatan fisik dan vitalitas adalah bagian penting dalam kebahagiaan seseorang.

\section{Media Sosial}

Menurut Kamus Bahasa Indonesia, media adalah alat, sarana komunikasi, perantara, atau penghubung. Sosial artinya berkenaan dengan masyarakat atau suka memperhatikan kepentingan umum.Dari sisi bahasa, media sosial dapat dimaknai sebagai sarana yang menghubungkan masyarakat untuk berkomunikasidan berbagi. Media sosial merupakan medium atau wadah untuk bersosialisasi dengan menggunakan teknologi berbasis web untuk menyebarluaskan secara pengetahuan dan informasi secara cepat kepada seluruh pengguna internet didunia. Menurut Juliasih dalam Kristanto (2011) media sosial adalah media yang sering disebut sebagai media online dimana dapat mewakili para penggunanya untuk saling berinteraksi dengan sesamanya di dunia luar baik yang dikenal maupun tidak.

\section{Hasil Penelitian dan Pembahasan}

Secara keseluruhan hasil data yang diperoleh dari responden, terlihat bahwa sebagian besar responden memiliki tingkat happiness yang tinggi sebanyak 98,3\% dan sisanya memiliki tingkat happiness yang rendah. Hal tersebut didukung pula oleh aspek-aspek happiness seperti positive emotion, engagement, relationships, meaning, accomplishment, dan health yang juga memliki tingkatan yang cenderung tinggi, serta tingkat negative emotion yang rendah.

Dari hasil ambil data lapangan yang dilakukan oleh peneliti, terlihat bahwa seluruh mahasiswa yang menjadi responden atau subjek penelitian ini cenderung memiliki tingkat kebahagiaan yang tinggi. Hal tersebut dikarenakan seluruh aspek yang dimaksud rata-rata 
bernilai tinggi, antara lain positive emotion sebanyak 95\%, engagement sebanyak 95\%, relationships sebanyak $100 \%$, meaning sebanyak $96,7 \%$, accomplishment sebanyak $95 \%$, negative emotion sebanyak $18,3 \%$, serta health sebanyak $96,7 \%$. Maka kesluruhan aspeknya dapat ditarik kesimpulan bahwa sebanyak $98,3 \%$ responden atau mahasiswa pengguna media sosial memiliki tingkat happiness yang tinggi.

Dapat dikatakan bahwa penelitian ini tidak banyak kesamaan dengan penelitian lain, karena terlihat bahwa ternyata media sosial lebih dirasa menimbulkan hal-hal yang lebih positif dibanding negatif oleh seluruh responden yang terlibat.

\section{Kesimpulan}

Seligman mengatakan bahwa kebahagiaan merupakan suatu hasil penilaian terhadap diri dan hidup, yang memuat emosi positif seperti kenyamanan dan kegembiraan yang meluap-luap, maupun aktivitas positif yang tidak memenuhi komponen emosi apapun seperti absorbsi dan keterlibatan (Seligman, 2005). Komponen yang ada pada teori ini antara lain adalah positive emotion meliputi perasaan bahagia, senang, nyaman, berhasrat, dan sebagainya. Emosi positif juga meliputi perasaan optimis terhadap kehidupannya di masa lalu, saat ini, dan masa depan. Engangement yaitu menemukan aktivitas yang membutuhkan keterikatan penuh. Keterikatan dalam aktivitas kehidupan kita merupakan hal yang penting untuk dipelajari, ditumbuhkan dan dipertahankan untuk kebahagiaan diri. Relationships yang merupakan salah satu dari aspek penting dalam kehidupan. Manusia merupakan makhluk sosial yang mengembangkan hubungan dengan pesat, cinta, intimasi, dan emosi yang kuat serta interaksi fisik dengan manusia lain, sehingga menumbuhkn kebahagiaan. Meaning yang merupakan tujuan dalam kehidupan, mampu menentukan arah hidu, merasa bahwa hidup itu bernilai dan layak untuk dinikmati, serta terlibat dnegan sesuatu yang lebih besar dari dirinya. Accomplishment atau memiliki tujuan dan ambisi dalam kehidupan yang dapat membantu kita dalam meraih sesuatu yang dapat memberi kita rasa pencapaian diri untuk mendorong kita agar tumbuh dan berkembang. Kemudian ada Negative Emotion, sebenarnya bukan merupakan bagian dari model PERMA, namun merupakan bagian dari emosi. Emosi negtaif meliputi perasaanperasaan seperti sedih, cemas, dan marah. Terakhir adalah aspek health, walaupun kesehatan (health) bukan merupakan bagian dari model PERMA, kesehatan fisik dan vitalitas adalah bagian yang penting pula dalam kebahagiaan seseorang. dengan menggunakan teknologi tinggi dan sangat memperhatikan kesehatan bagi penggunanya.

\section{Saran}

\section{Saran untuk subjek penelitian}

1. Subjek yang merasakan dampak positif, diharapkan tetap memanfaatkan media sosial dengan baik dan menggunakannya dengan bijak untuk berbagai hal, seperti media edukasi, silaturahmi, dan bahkan sebagai hiburan.

2. Subjek yang merasakan dampak negatif, diharapkan mampu membatasi kegiatannya dalam mengakses sosial media, mencari aktifitas lain di dunia nyata agar lebih terfokus pada interaksi yang real. Namun diharapkan pula untuk tetap mengikuti perkembangan zaman yang bisa lebih banyak mendapat informasi dan pengetahuan lain dari media sosial.

\section{Saran untuk penelit selanjutnya}

1. Diharapkan dapat lebih mengerucutkan subjek penelitiannya, beserta kemungkinan faktor-faktor yang muncul dari perilaku yang diteliti.

2. Memperbanyak jumlah responden.

3. Lebih rinci mengklasifikasikan karakter subjek yang akan diteliti.

4. Menambah referensi literatur.

\section{Daftar Pustaka}

[1] Alan, A. K., \& Kabadayi, E. T. (2016). The effect of personal factors on social media usage of young consumers. Procedia - Social and Behavioral Dciences. 235, 595-602. 
https://doi.org/10.1016/j.sbspro.2016.11.086.

[2] Andreas, Kaplan M., Haenlein Michael 2010. "Users of the world, unite! The challenges and opportunities of social media". Business Horizons 53 (1). p. 61.

[3] Argyle, Michael. (2001). The Psychology of Happiness, 2nd Edition. New York: Routledge.

[4] Carr, Alan. (2004). Positive Psychology. The Science of Happiness and Human Strengths. New York: Brunner Routledge.

[5] Diener, E. (2006). Guidelines for national indicators of subjective well-being and ill-being. Applied research in quality of life, 1 (2), 151-157.

[6] Diener, E. (2000). Subjective well-being: The science of happiness and proposal for a national index. American Psychologist, 55 (1), 34-43. PsycARTICLES.

[7] Diener, E., Lucas, Richard E., Oishi, Shigero. (2005). Subjective Well Being: The Science of Happiness and Life Satisfaction. Handbook of Positive Psychology 68-70. New York: Oxford University Press.

[8] Kolloh, Dina Yohanna. (2015). Hubungan antara subjective well-being dengan internet addiction remaja. Salatiga. Fakultas Psikologi Universitas Kristen Satya Wacana.

[9] PUSKAKOM-UI. (2015). Profil pengguna internet Indonesia 2014. Jakarta: Asosiasi Penyedia Jasa Internet Indonesia.

[10] Putri, Novrita Ade. (2013). Subjective well-being pada mahasiswa yang menggunakan internet secara berlebihan. Surabaya. Fakultas psikologi universitas surabaya.

[11] Seligman E. P, Martin (2005). Authentic Happiness. Bandung : PT. Mizan Pustaka 